\title{
Net Gains? Pacific Studies in Cyberspace
}

\section{Terence Wesley-Smith}

\begin{abstract}
C yberspace, an electronic universe created by a vast network of computers, is fast becoming the new frontier in education. Since the midI990s, universities in North America and elsewhere have actively been exploring the potential of the Internet and World Wide Web for the distribution of educational materials. Like most frontier situations, the educational push into cyberspace is facilitated by advances in technology and often motivated by economic and strategic rather than academic considerations. Spurred on by the emergence of virtual universities like University of Phoenix Online and Walden University, university administrators are rushing to deliver courses and degree programs to students attracted by the "anywhere, anytime" flexibility of online options. Unfortunately, the scramble for cyberspace has little to do with the possible educational justifications for these new pedagogies. The literature on online teaching and learning tends to be heavy on "how to do it" and light on underlying educational theory or philosophy. As yet, there is little information on the impact of all of this on student learning or performance (Schutte 1996).

The implications for international forms of education are even less clear. As with other aspects of globalization, western commentators have tended to emphasize the egalitarian or leveling qualities of cyberspace. Philip Elmer-DeWitt has argued that cyberspace is "about people using the new technology to do what they are genetically programmed to do: communicate with one another. . . Stripped of the external trappings of wealth, power, beauty, social status, people tend to be judged in the Cyberspace of the Internet only by their ideas and their ability to get them across in terse, vigorous prose" (quoted in Colón I995). However, it is by no means a neutral social environment. Cyberspace has an intrinsic set of cultural characteristics determined by its peculiar compression of space and time as well by the dominance of text-based rather than face-to-face commu-

The Contemporary Pacific, Volume I5, Number I, Spring 2003, II7-I36

(C) 2003 by University of Hawai'i Press
\end{abstract}


nications. As Carlos Colón has pointed out, these texts carry important cultural meanings: "It is not the real universe, it is a virtual universe made out of signs. It is a semiotician's heaven" (Colón 1995). At best, this suggests great potential for misunderstanding in cross-cultural educational situations. At worst, it raises the possibility that, as with other global media, cyberspace will become dominated by particular cultural signs and forms, an unbounded ether for the spread of western discourses, ontologies, and epistemologies. These crucial aspects also remain largely unexplored as the virtual frontier continues its inexorable advance overseas.

In Oceania, issues of access and control raise further questions about whether the spread of these forms of communication will reduce or exacerbate existing imbalances of power. Internet users in the Pacific Islands operate within a political economy of access over which they have little control. For cost and other reasons, only a relatively small number of residents are connected to the Internet, and many Pacific-related websites are hosted by institutions located in metropolitan countries like Australia, New Zealand, or the United States (Ogden 1995; 1999). As a result, most Pacific-related Internet traffic takes place either between people residing outside the region, or between those in urban centers in the region and the outside world. This cyberdiscourse is often about the Pacific Islands rather than for Pacific Islanders, and the most active Islander participants are resident overseas. Few strands of the web embrace the sea of islands itself, and Islanders have little control over the way their societies are imagined in the electronic impulses of cyberspace.

Cyberspace is not yet widely used for educational purposes in Oceania. The major distance-learning initiatives in the region have been built around technologies that are more elaborate. For example, the University of the South Pacific recently launched USPNet-2000, a largely Japanesefunded, state-of-the-art satellite telecommunications system linking campuses in its twelve member countries. This replaces a radio communications system established in 1974 and is used mainly to deliver course materials from the main campus in Suva to remote sites via video and audio transmissions (USP 2000). ${ }^{1}$ The University of the South Pacific and other universities in the region are, of course, connected to the Internet, and faculty and students increasingly use it for email and to access overseas library and other resources. Although developing online courses or degree programs is not a priority for regional institutions, it is probably only a matter of time before students in Oceania become consumers of such educational materials. The danger is that these virtual products will 
be delivered by educational institutions in Australia, New Zealand, or the United States, devoid of local content and with little regard for cultural and other sensibilities. This would represent a setback for educators who have worked hard to enhance the local relevance of regional educational systems in the postcolonial era (see, eg, Thaman 1993).

In this paper, I explore how the Internet might be used to enhance the quality of teaching and learning in Pacific Islands studies, an interdisciplinary field of study focused on the region. I do so with reference to an ongoing initiative in the University of Hawai'i's School of Hawaiian, Asian, and Pacific Studies called Moving Cultures: Remaking Asia-Pacific Studies, funded by the Ford Foundation as part of a larger effort to rethink "area studies" in the United States. ${ }^{2}$ I will argue that, if used carefully, interactive technology can facilitate new and more effective ways of learning in and about the region. Perhaps more important, I hope to demonstrate that computer-mediated and other interactive pedagogies have the potential to redress some of the power imbalances apparent in the field (as well as in cyberspace) and help accelerate the process of decolonization that has been underway for some years.

\section{Decolonizing Pacific Islands Studies}

Pacific Islands studies is a loosely organized field of inquiry based on a wide range of literatures about the region drawn mainly from disciplines in the social sciences and humanities. It exists as a regional subfield or emphasis within those disciplines, as well as in the form of interdisciplinary teaching or research programs at a number of universities in Hawai' $i$, Guam, Australia, New Zealand, North America, Europe, and Asia (Wesley-Smith 1995; Crocombe 1987). Although not linked by a single professional association, practitioners in the field meet regularly at conferences sponsored by Pacific studies centers, the Pacific History Association, the Association for Social Anthropology in Oceania, or the Pacific Islands Political Studies Association. They often publish their work in scholarly journals such as Pacific Studies, The Journal of Pacific History, and The Contemporary Pacific. The field is coherent enough to identify several important general characteristics.

The origins of the field of Pacific Islands studies are inextricably tied to the colonial history of the region, and the legacies of that relationship are readily apparent today. The oldest established and arguably most influential centers for Pacific Islands studies are located outside the region (at 
least as it is usually defined) in metropolitan countries such as the United States, Australia, and New Zealand. An important rationale for their establishment and subsequent funding has been to generate information about and increase understanding of the Pacific Islands places with which these regional powers have had to deal. It is not surprising, for example, that the structure and emphasis of Pacific studies programs in Australia have tended to reflect the Australian national interest in particular parts of the region, and in particular issues of concern to policy makers in Canberra. Similarly, the origins of the Center for Pacific Islands Studies (then the Pacific Islands Studies Program) at University of Hawai'i are associated with US involvement in Micronesia after World War II and with a perceived need for Americans to know about this part of the world (WesleySmith I995).

Although the pragmatic "need to know" rationale has always been an important element in the funding of language and area studies programs in metropolitan countries, most practitioners become involved for quite different reasons. For anthropologists and other social scientists, the Pacific Islands area has often represented a giant laboratory to pursue the esoteric questions and concerns of their disciplines. While many become deeply involved in the affairs of host or subject communities, most of the knowledge produced from their research takes the form of scholarly monographs and papers destined to be consumed by a narrow circle of specialists whose material, cultural, and intellectual lives are far removed from those represented in these studies. Much of this activity has little if any relevance for the daily needs and concerns of Pacific Islanders. According to Māori educator Linda Tuhiwai Smith, such research embodies "a cultural orientation, a set of values, a different conceptualization of such things as time, space, and subjectivity, different and competing theories of knowledge, highly specialized forms of language, and structures of power" $(\mathrm{I} 999,42)$. Pacific lives and concerns are represented in these texts in ways that Islander readers sometimes find alienating. Smith has argued that "reading and interpretation present problems when we do not see ourselves in the text. There are problems, too, when we do see ourselves but can barely recognize ourselves through the representation" (I999, 35).

The need to decolonize Pacific Islands studies has long been recognized, although there is still considerable disagreement regarding exactly what that involves and how it might be fully realized. The increasing participation of Pacific Islanders in Pacific-related research, teaching, and administrative positions is clearly an important development in this respect. While 
Pacific Islanders are still markedly underrepresented in Pacific branches of key disciplines such as history and anthropology, Islanders now staff and direct many, but not all, of the specialized programs for Pacific studies. More and more Pacific Islanders participate in Pacific-related academic conferences, although many of these events are still dominated by what Robert Borofsky calls "outlanders" (Borofsky 2000, 7). ${ }^{3}$ The situation in publishing is more complex and perhaps less encouraging. "Pacific Islands" or "Pacific Studies" lists of mainstream academic presses do include works by Pacific Islanders, but they remain a small minority. Similarly, although Pacific Islanders are much better represented than they used to be in the pages of refereed journals like Pacific Studies and The Contemporary Pacific, most main articles are still authored by non-Pacific Islanders. ${ }^{4}$ The emergence of publishing ventures specifically devoted to island voices and perspectives has helped counter the dominance of expatriate authors to some extent. The Institute of Pacific Studies at the University of the South Pacific has had an extensive publishing program since the early I970s, and a number of other Islander-oriented presses and journals have emerged in the region in more recent years. ${ }^{5}$

In an important sense, however, the changing demographics of Pacific Islands studies does not guarantee the decolonization of the field. If the social science and humanities enterprises that lie at the heart of Pacific Islands studies discourse are embedded in an academic culture that is thoroughly western in its origins and values, then the work of decolonization goes far beyond a mere changing of the guard in the halls of academe. According to Smith, the danger is that western-trained Islander academics will simply reproduce and even reinforce the modes of research and representation that she argues are essentially "hostile" to indigenous peoples and concerns (1999, 36). As David Welchman Gegeo and Karen WatsonGegeo noted: "Former colonized peoples are experiencing a transformation in which for them decolonization is at the epistemic level: they are questioning Anglo-European knowledge and its relevance for solving problems and representing reality. They are increasingly speaking from their indigenous ontologies and epistemologies" (ND, 28; see also Gegeo and Watson-Gegeo 2002). Similarly, staff members at the University of the South Pacific have recently advocated the establishment of a Pacific studies program at the Laucala campus that examines the Pacific "from the inside out." As Elise Huffer stated in the preconference discussion posted on the Center for Pacific Islands Studies website from September 2000 onward: 6 "Building a Pacific pedagogy requires moving away from a for- 
mal, discipline-based perspective. We must enter the world of the Pacific and learn from the concepts, values and rituals which guide island societies. Existing systems of knowledge and beliefs and their practices must be brought to life within the university setting, as they are in society at large." 7

Decolonizing the field then becomes a complex process not just of reclaiming a discourse long controlled by outsiders, but reconstituting it to reflect and empower Oceanic worldviews, ways of knowing, and material interests. These concerns are perhaps most apparent in the creative writings of authors like Albert Wendt, Konai Helu Thaman, and Patricia Grace, and in the analytical work of scholars such as Epeli Hau'ofa, Lilikalā Kame'eleihiwa, and Vilsoni Hereniko. However, as these writers would probably agree, this is a long-term process of rehabilitation and recovery that has only just begun, given the likely persistence of western approaches to inquiry, albeit in altered forms. According to Hereniko, "Shunning the benefits of world systems is no longer an option; domesticating them is a much more attractive alternative" (Hereniko I995, I40).

\section{Pacific Studies and Interactive Pedagogy}

The area studies classroom is clearly an important site for the reproduction of hegemonic discourses about Oceanic "others." But it is also a place where such discourses can be resisted and, under certain conditions, even subverted and replaced. Obviously, an important part of decolonizing the classroom has to do with curriculum and content. Some University of Hawai'i courses, like Hawai'i: Center of the Pacific (HWST I07) or Myths of Hawaiian History (HWST 343) even embody the challenge in their titles. Others accelerate the decolonization process by focusing on materials intimately connected to indigenous identities or cultural sensibilities, such as Ka Ho'okele Holokabiki: Hawaiian Voyaging (Hwst 397). A particularly striking example comes from the field of literature at the University of Hawaili where a course (Literature of the Pacific, PACs/ENG 37I) that used to focus on European writings about the Pacific now focuses almost exclusively on the indigenous writers of the region, using a critical text appropriately called Inside Out: Literature, Cultural Politics, and Identity in the New Pacific (Hereniko and Wilson I999).

However, revised content is not enough, in itself, to liberate Pacific Islands studies from its colonial past. After all, as Edward Said pointed out more than two decades ago, part of what makes western discourse hege- 
monic is the support it receives from "institutions, vocabulary, scholarship, imagery" $(1978,2)$. The danger is that western ethnocentrism, or what Said called "orientalism," is often replaced in nonwestern scholarship by indigenous ethnocentrism or "reverse orientalism," complete with its own set of hegemonic institutions and practices (Alatas 1993, 3I3). For Said, whose work has done much to reveal the mechanisms of western hegemony, this is an unfortunate outcome, condemning its practitioners "to an impoverished politics of knowledge based only on the assertion and reassertion of identity" (I99I, 24). Part of the solution to this dilemma may lie in the development of new, more critical and student-centered models of teaching and learning.

Most universities still employ a lecture-based, objectivist model of teaching and learning in their undergraduate programs. Here the central activity involves a teacher delivering material to a large group of learners. The teacher structures the material, addresses the students as a group, and generally controls the style and pace of learning. Students learn by listening and by doing assigned readings, often from a textbook. This is a practical and cost-effective way of dealing with large numbers of students, who are often socialized into this style of learning from an early age. However, not only does it depend for its success on the communication skill and dynamism of the instructor, but it also encourages essentially passive forms of learning. Students learn to "play the game" according to rules established by someone else and often have little incentive to engage the subject matter actively and critically. Opportunities for active learning may only occur in small group discussions or tutorials, if these are part of the course, or perhaps in writing assignments, especially when these involve library or other types of research.

Not only are more active, student-centered approaches to learning more likely to be rewarding to the student, but they may also help generate forms of academic discourse that are open-ended and inclusive. Advocates of this type of learning draw their theoretical inspiration from the cognitive movement in psychology, which "portrays learners as active processors of information," and proposes that "what learners do to enrich information ... determines the level of understanding they ultimately achieve" (Bruning I995, I). In this constructivist model of learning, students are encouraged to explore topics for themselves, discover information, and reflect on what they come up with. They construct rather than simply acquire knowledge, create rather than simply learn meaning, and generally exercise more control over the process of their own education (Hofstetter 
1997). For most experienced teachers, these ideas make good senseeven if many of us continue to find reasons not to bring these practices to the classroom. Certainly, Edward Said appeared to endorse the general approach when he urged students not to read texts as though they were sacred or in order to venerate their authority: "What the reading of texts should leave you with is an appetite for asking more questions.... How did this come about? Where did that come from? What are the uses to which it can be put? ... As a teacher, I believe it is absolutely central that my role is not to tell students to become my disciples. On the contrary, I should say what I have to say and encourage students to question it" (2000, 448).

The constructivist approach to teaching and learning has particular relevance in a rapidly decolonizing field like Pacific Islands studies. Unlike the top-down dynamics of the "sage on a stage" model of teaching inspired by behavioral psychology, constructivist educators assign an important role to the knowledge, experience, and perspectives that students bring to the classroom. This is increasingly important as Pacific Islands studies courses in Australia, New Zealand, the United States, and throughout the region itself, attract more students connected to Oceania by intimate ties of ancestry and cultural heritage. Although some Pacific Islands studies programs may originally have been created to teach outsiders about the region, today their clients increasingly identify with the region and engage with the subject matter in ways that are much more personal. ${ }^{8}$ These students are typically uncomfortable with western academia's penchant for detached and dispassionate teaching and learning styles, as well as its tendency to objectify other peoples and cultures and treat them as peripheral players in the "real world" of global politics and economics. They demand that Pacific Islands studies programs join with Epeli Hau'ofa in asserting, "Oceania is us. We are the sea, we are the ocean, we must wake up to this ancient truth and together use it to overturn all hegemonic views that aim ultimately to confine us again" (I994, I60). Above all, they expect their own knowledge of and experience with Oceania to be acknowledged and affirmed as an important part of the educational experience.

The application of constructivist principles requires some radical changes in teaching and learning practices. The primary aim of the instructor is no longer simply to transmit information about something, but to encourage and facilitate an active process of "knowledge formation" in students (Bruning I995, 216). He or she might, for example, put much more emphasis on discussion and debate and less on lectures, and encour- 
age students to search out supplementary or alternative sources of information. Assignments might allow more flexibility in the choice of topic and the form (or media) in which the finished product is delivered. Students might be encouraged to work in small groups on projects, and assessment might include an element of peer review. As students assume more responsibility for course content, instructors inevitably lose some of the control they exercised before. However, their new role as "guide on the side" is no less demanding, requiring more frequent one-on-one counseling interactions with students, as well as careful and constant planning to facilitate peer learning.

Sophisticated communications technologies offer the possibility of transcending the limits of both space and time inherent in the traditional classroom. Rather than being confined to the classroom, learners can be physically located anywhere in the world-provided they have access to suitable equipment. Furthermore, learning can occur at any time, rather than simply during scheduled classes. These powerful technologies can be used to facilitate and enhance constructivist approaches to teaching and learning. However, they are perhaps more frequently used for other purposes. Many forms of distance education, for example, use video or online technologies simply to reproduce traditional classroom practices. The electronic delivery of educational materials to remote sites may well provide valuable access to learners who might otherwise be excluded, but it does not necessarily encourage better, more empowering, ways of teaching and learning.

Constructivist approaches to education typically require a greater variety and frequency of interactions between students and instructors, between students and their peers, and between students and course materials, than conventional approaches. Communications technologies can be effectively used to facilitate and enhance the interactivity that lies at the heart of student-centered teaching and learning practices. Used appropriately, these technologies have the potential to improve the quality as well as the reach of education systems.

\section{Regional Learning Communities}

Participants in the Moving Cultures project at the University of Hawai' $i$ have recently developed a pedagogical model designed to address some of the imbalances of power that characterize Pacific Islands studies and other area-based educational programs. The model advocates the use of inter- 
active technologies to create dynamic links between places where area studies are taught and the places being studied. It suggests that the partner educational institutions collaborate in the development of shared curriculum, and advocates student-centered forms of teaching and learning in these multisited classrooms. It proposes, in other words, the formation of regional learning communities.

A primary purpose of the Moving Cultures model is to break down the "us" studying "them" dichotomy that has tended to characterize organized area studies programs from the beginning. With this in mind, participants from the University of Hawai'i have established partnerships with a number of educational institutions in the Asia-Pacific region to explore the multisited classroom idea. Courses or course modules are being developed in collaboration with the University of the South Pacific in Fiji, Canterbury and Victoria Universities in New Zealand, Ateneo de Zamboanga University in Mindanao in the Philippines, the National University of Singapore, and Ritsumeikan Asia Pacific University in Japan. These jointly owned courses are taught simultaneously at University of Hawai' $i$ and on the partner campuses, using interactive technologies such as email, websites, and videoconferencing to link participants at each site.

These interactive courses explore the nature and local implications of the global flows of capital, people, and ideas that affect each of these sites in profound ways. Modules have been developed to examine topics such as migration and multiculturalism; tourism, representation and identity; and globalization and popular culture. These are topics of immediate relevance to people in each of the regional sites, including Hawaili, which as quintessential Asia-Pacific border zones exhibit all of the tensions and contradictions inherent in the contemporary study of place and culture. The pedagogy is designed to give students an active role in shaping and exploring the topics in close collaboration with overseas counterparts, and to elicit personal experiences and perspectives. Materials and assignments are posted on class websites, which also host asynchronous discussions as well as real-time "chat" between participants. The websites record the results of these collaborative, participatory, and inductive experiments in knowledge production.

A scaled-down version of the original Moving Cultures pedagogical model focuses on the development of a series of interactive modules, each of which constitutes part of a longer course. This variation is much less complex and more flexible than the original model. Four- or five-week modules can more easily be developed collaboratively by a few cooperat- 
ing faculty on each campus and tailor-made to fit into courses regularly taught by those individuals. Inserting interactive modules into existing courses also bypasses the bureaucratic and other difficulties associated with establishing entirely new courses and avoids the potential problem of recruiting students for courses that are not part of the regular offerings. Limiting the period of intercampus interactivity avoids some of the planning and management difficulties associated with the fact that regional campuses often follow quite different academic calendars. The interactive modules can readily be scheduled to occur during overlap periods when both campuses are in session.

This was the model used in a recent collaboration between University of Hawai'i's Center for Pacific Islands Studies and the Department of History at Canterbury University in Christchurch, Aotearoa New Zealand.

\section{Testing the Model: Oceania on the Move}

The University of Hawai'i-University of Canterbury collaboration in the year 2000 yielded valuable insights into the joys and tribulations of international forms of interactive teaching and learning. In a sense, the collaboration came about by default. Originally Canterbury joined the University of Hawai'i-University of the South Pacific consortium with a view to participating in one module of the proposed Moving Cultures course, scheduled to occur in the second half of the year 2000 . When a coup in Fiji forced the postponement of the course, it was decided to proceed with a modified, two-campus version of the venture. The result was a fourweek interactive module on migration taught simultaneously as part of a Pacific history course at Canterbury and a Pacific Islands studies course at University of Hawaici. ${ }^{9}$

The contents of the "Oceania on the Move" module were developed by the collaborating instructors (mainly using email and a website) to reflect the particular migration experiences of Hawai'i and Aotearoa New Zealand, as well as topical interest in the ongoing political crisis in Fiji. The general topic for the first week was "Ancestral Journeys," which surveyed the original settlement of the region and pre-European mobility. In "Moving In," the topic for week two, we looked at migration into Oceania during the colonial period, with particular reference to Asian migration into Hawai' $i$ and Fiji. The following week the topic shifted to "Islanders on the Move," which considered contemporary patterns of out-migration and the formation of diasporic communities by Islanders, particularly in New 
Zealand. The final topic, "Living Together," was designed to explore the contemporary social, cultural, and political implications of migration in Hawai'i, New Zealand, and Fiji, with particular reference to the interests of indigenous communities.

The instructors followed the same syllabus and used class meeting times to deliver summary lectures, discuss the issues, provide advice on student assignments, and reflect on the growing contents of the Oceania on the Move website. Most of the interactive component of the course occurred on this website, operated under the auspices of University of Hawai'i's Mānoa Advanced Interactive Learning Environment (MAILE) system, but fully accessible to participants at Canterbury. ${ }^{10}$ Here, at any time, participants could access materials (such as the course syllabus and information about assignments), read each other's work, participate in threaded discussions of course-related issues, or engage in informal, real-time "chat." The weekly assignments were designed to elicit critical responses to course materials and to encourage discussion informed by personal experiences and perspectives. Students often worked on assignments in small intercampus groups, or with other participants from their own campus in smaller subsets of those groups. Sometimes they were asked to respond individually.

The initial assignment required the students to find out about each others' histories of movement. Although this "migration biographies" exercise was designed to use life experiences to explore the reasons people move from one place to another, it also allowed participants to get to know a bit about each other through informal email exchanges. In two of the assignments, some groups had to construct brief answers to relatively open-ended questions posed by the instructors, while other groups were asked to comment on those responses. For the final assignment, all students participated on the website in an open discussion of key issues.

Although the Oceania on the Move module required considerably more planning and management than a conventional course, the results of the experiment exceeded both instructors' expectations. As Canterbury instructor Peter Hempenstall put it in his final website posting, "Everyone here at UC agrees this module has been a winner... I personally hope that we can regularize such interactive learning for both campuses." 11 Students on both campuses also seemed to find the experience rewarding. Early in the module, one UH student headed his response to an assignment "Excellent Exercise" and went on to express his appreciation for the "opportunity to get acquainted with you all via this wonderful form of technology known 
as the Internet." In their posted comments at the end of the module, UC students variously described the experience as "very memorable," "stimulating," "very exciting," and "tu meke" (too much, ie, "cool”). One wrote, "I have enjoyed and gained more from this type of interactive learning than I ever envisaged." A self-described Luddite found the module "both scary and exciting. It has been really interesting reading and learning the views of the Pacific that our Hawaiian friends have.... I have enjoyed this immensely."

A strong element of complementarity between the sites contributed to the success of the exchange. Students undoubtedly learned much from peer analyses of the weekly readings posted on the website. When Fiji-related issues were discussed, for example, everyone learned from everyone else. But what really made this experience "memorable" and "exciting" was the place- and culture-based knowledge that participants brought to the conversation. The dialogue was significantly richer when it was informed by familiarity with the societies featured in the module and by personal experience with the issues discussed. This was the element that allowed Hawai'i-based students to learn much more about New Zealand-related issues than they could from readings alone. The reverse was also clearly the case for one Canterbury student who wrote that "it has been fantastic to get an insight into and gain understanding of the culture of Hawai' $i$, indigenous Hawaiian issues, and the migration that resulted in a multicultural society."

The diversity of the group participating in Oceania on the Move was striking and another important factor in the dynamics of the exchange. Participants included individuals from Papua New Guinea and Guam, as well as students of Hawaiian, Okinawan, Marshallese, Fijian-Tongan, Samoan, and Caucasian ancestry. This cultural and ethnic diversity added a rich dimension to the discussion, with students drawing on their distinctive backgrounds to illustrate points or expand on issues arising from course materials. However, the exchange was somewhat skewed because the University of Hawai'i group was significantly more diverse than the Canterbury one.

Other differences in academic style and approach also affected the exchange in significant ways. By the end of the four weeks, the discussion threads on the website were generally much more lively-and interesting - than they had been earlier in the module. As Peter Hempenstall noted, the module was "just heating up as we had to turn the heat down ... because of the end of the semester." This "heating up" may have largely 
reflected a growing level of comfort with what for most participants was an unfamiliar mode of learning. However, some participants found it more difficult to "unlearn" familiar academic practices to suit the new medium. From the beginning, Canterbury students' postings tended to be rather more scholarly than those from University of Hawai'i. They were also more formal and detached in style, prompting one $\mathrm{UH}$ student (attired in surf shorts and t-shirt) to remark that his Canterbury counterparts "must all wear suits." As a Canterbury participant reflected apologetically in her final posting, "It WAS pretty hard getting into the swing of things and I personally felt it hard to communicate on that informal basis which I think was being encouraged by you guys, but I think that was just because I kept thinking of everything STRICTLY as an academic task or whatever. "Yawn*. Sorry."

Although most participants seemed enthusiastic about Oceania on the Move, they also expressed a strong sense that its interactive potential had not been fully realized. One Canterbury student probably spoke for many when she suggested that "a more active interaction could've taken place between our two campuses." Students were required to respond to each others' work throughout the module, but only a relatively small portion of the interchange had a spontaneous quality. Although many of the postings on the discussion board raised interesting or provocative points, relatively few of the issues were taken up by other participants; when they were, the threaded conversations were usually not sustained for very long. Part of the problem was the timing of the module, which occurred in the last four weeks of Canterbury's school year when students were busy with numerous other end-of-semester chores. Probably more important was the nature of the assignments, which might have been designed to put more emphasis on the sort of open-ended discussion that occurred in the last week of the module, and rather less on summarizing and critiquing the weekly readings. Students may not have had the time or inclination to engage in additional discussion once their weekly assignments were posted.

It might also have been useful to build in more real-time interactions to complement the asynchronous exchanges occurring on the discussion board. Students were free to use the website's real-time chat function as they wished, potentially a very valuable way for participants to develop a sense of community. Students were clearly interested in this function and would usually check it out each time they logged onto the website. At times there were sustained conversations on a number of topics, including surfing, cars, music, television shows, and the Olympic games. However, more often than not, participants would enter, find no action, and leave. ${ }^{12}$ 
As one student noted, “Chatrooms don't work when you're the only person in there, or when you are the only one TALKING!!” Another frustrated student put the matter more succinctly when he complained, "Our use of the chatroom sucks!!" It would have been relatively easy to designate a certain period of time during the week when all participants were required to visit the site to take care of housekeeping matters, discuss how the module was progressing-and chat.

\section{Toward Pacific Studies in Cyberspace}

Pacific Islands studies is changing rapidly, from a field originally intended to serve external political and scholarly interests to one firmly committed to the interests of the region itself. This is a complex transition, which involves fundamental shifts in approach as well as content. The challenge is not only to make the subject matter more island-centered, but also to create a learning environment in which indigenous perspectives, ontologies, and epistemologies are more readily recognized and validated. The purpose here is not necessarily to banish western scholarly approaches, even if that were possible. Rather, as Said and others have argued, the ultimate objective is to reduce the hegemony of western approaches and representations by privileging discourses more firmly rooted in the cultural landscapes of Oceania.

The adoption of student-centered pedagogical practices can hasten the decolonization (and recolonization) of the field by encouraging more open-ended, flexible, and empowering modes of teaching and learning. Constructivist approaches to teaching and learning can, and should, be employed in conventional Pacific Islands studies classrooms. Such practices can also be supplemented by the use of computer-based communication technologies, which provide students with a convenient way to access course materials as well as to interact with each other and the instructor beyond the confines of the classroom. More important, and as the Oceania on the Move experiment demonstrates, Internet and web-based technologies can also facilitate significant interactions between students in different parts of the region. This is not something that can be replicated in the conventional classroom, except perhaps through student exchange programs. While real exchanges are expensive and usually involve only a small number of individuals, virtual exchanges are relatively cheap and can include larger numbers of participants. Furthermore, this model of interactive teaching and learning is flexible, and could, in theory, be adapted to link any number of courses and classrooms across the region and beyond. 
However, as experience with the Moving Cultures project suggests, regional learning communities are not always easy to establish. The whole approach depends for its success on a genuinely collaborative relationship between educational institutions that may have quite different resources, policies, practices, and priorities. All parties must be equally convinced of the value of the exercise and satisfied that their particular concerns and interests are being addressed as the project develops. Misunderstandings may arise, especially in cross-cultural settings, regarding who does (and pays for) what. The Oceania on the Move collaboration worked relatively smoothly largely because only a few people were involved in the planning, communications remained good, and each institution took care of its own resource needs.

These sorts of initiatives can also encounter major obstacles on the home front. Gerhard Fischer discussed his frustration at receiving negative student evaluations for an interactive course that he had worked hard to develop at the University of Colorado at Boulder. He noted that such innovative ventures involve significant risk for both faculty and students. Faculty members are not necessarily rewarded for such risk-taking by the institution, nor in his case by the students who took the course. Fischer suggested that faculty often underestimate the "culture shock" experienced in such courses by students accustomed to much more structured learning environments and "driven to learn primarily by the desire to get a good grade rather than by interest, passion, enjoyment" $(1998,3)$. Although many of the participants in Oceania on the Move exhibited "interest, passion, and enjoyment," the persistence of orthodox writing styles, as well as some conspicuous silences on the discussion board, may have been symptoms of discomfort or even resistance.

A key question is the extent to which these virtual "learning communities" can actually develop some meaningful sense of community (compare Howard 1999). This is important because the type of interactive learning advocated here requires that participants at least feel comfortable enough to converse freely about sensitive issues. The Oceania on the Move experience does not shed much light on this issue, although at times the campus groups appeared to operate more like opposing debating teams than members of a common community. There are complex cultural issues involved here, but it seems safe to assume that the potential for intercampus polarization will increase in tandem with the cultural distance between the collaborating sites. A sense of community probably takes longer to emerge in cyberspace than in the face-to-face situation of the conventional 
classroom. Community-building efforts might include posting short bios and photographs on the website, video conferencing, and assignments designed to encourage informal email partnerships between participants on different campuses.

Indigenous voices and ways of knowing are not yet well represented, either in Pacific Islands studies or in cyberspace. The development of regional learning communities might hasten the decolonization of both. These are urgent tasks if Pacific Islands studies is to retain its legitimacy and relevance in the postcolonial era.

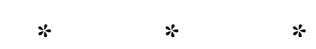

Thanks to Linley Chapman, Gerard Finin, Jaishree Odin, and Vilsoni Hereniko who made useful comments on earlier versions of this paper. Special thanks to Peter Hempenstall for helping make Oceania on the Move such a memorable experience. I remain entirely responsible for the contents of this paper.

\section{Notes}

I It is worth noting that the major emphasis within the USPNet system at present is on delivery of materials from the center to the periphery, rather than on interactivity, although students do have the opportunity to "talk back" to their instructors in Suva.

2 Information about this three-year project is available on the Moving Cultures website <www.hawaii.edu/movingcultures/>

3 Teresia Teaiwa has described the increasing influence of Islander scholars at these meetings (200I).

4 Approximately 30 percent of the lead articles and dialogue pieces in the first thirteen volumes of The Contemporary Pacific were authored by Islanders.

5 For example, He Pukenga Kōrero: A Journal of Māori Studies was launched in 1995 , followed by 'Ōiwi: A Native Hawaiian Journal in 1998.

6 Although the link to the discussion board was discontinued in preparation for the center's $200 \mathrm{I}$ conference, the preconference webpage for the $2000 \mathrm{con}-$ ference can be found at <http://www.hawaii.edu/cpis/conference/preconfdisc. html>

7 One of the most significant recent developments has been the recognition of Pacific studies as an academic priority area by the University of the South Pacific (see Naidu I998).

8 The Centre for Pacific Studies at Auckland University was established in 1980, in large part to serve the needs of Polynesian diasporic communities in Auckland. More than 70 percent of students currently enrolled during the 
2000-200 I academic year for the master's degree in Pacific Islands studies at the University of Hawai'i are of Hawaiian or Pacific Islands ancestry.

9 The courses were The South Pacific: Reading Cultural Encounters (HIST 363), and The Contemporary Pacific (PACS 49I).

IO MAILE offered a convenient website environment with features similar to those of the widely used Web-CT and Blackboard systems. It has since been phased out by the UH Outreach College and replaced by Blackboard.

I I All of the quotations in this section are from materials posted on the Oceania on the Move website. To preserve confidentiality, students are not identified by name. For similar reasons, access to the website is limited to participants only.

I 2 The website recorded a long list of visitors to the chatroom, and plaintive messages like "hello?" or "is there anybody out there?"

\section{References}

Alatas, Syed Farid

I993 On the Indigenization of Academic Discourse. Alternatives I 8: 307338.

Borofsky, Robert

2000 An Invitation. In Remembrance of Pacific Pasts: An Invitation to Remake History, edited by Robert Borofsky, I-30. Honolulu: University of Hawai'i Press.

Bruning, Roger $\mathrm{H}$

I995 Introduction. In Cognitive Psychology and Instruction, edited by Roger Bruning, Gregg Schraw, and Roy R Ronning, I-22. Englewood Cliffs, NJ: Prentice Hall.

Colón, Carlos

I995 Semiotics in Cyberspace. In the P550 Cognition and Semiotics website [P550 is a graduate level course offered by the School of Education at Indiana University, Bloomington]: < http://php.indiana.edu/ ccolon / Semiotics / ccolon3.html >

Crocombe, Ron

I987 Studying the Pacific: Past Experience and Future Potentials. In Class and Culture in the South Pacific, edited by Antony Hooper, Steve Britton, Ron Crocombe, Judith Huntsman, and Cluny Macpherson, I I 5-I39. Auckland: Center for Pacific Studies, University of Auckland; Suva: Institute of Pacific Studies, University of the South Pacific.

Fischer, Gerhard

I998 Creating the University of the 2ist Century: Cultural Change and Risk Taking. Consequences of and Reflections on Teaching an Experimental Course. Report, University of Colorado, Boulder, Center for Lifelong Learning and Design and Department of Computer Science, I9 
October < http://www.cs.colorado.edu/ gerhard/reports/cu-risk taking I998.pdf $>$

Gegeo, David Welchman and Karen Watson-Gegeo

ND Colliding Semiotics: The Hermeneutics of Indigenous Versus AngloEuropean Discourses on Interethnic Conflict. Manuscript.

2002 The Critical Villager: Transforming Language and Education in Solomon Islands. In Language Policies in Education: Critical Issues, edited by James W Tollefson, 309-325. Mahwah, NJ: Lawrence Erlbaum Associates.

Hau'ofa, Epeli

I993 Our Sea of Islands. In A New Oceania: Rediscovering Our Sea of Islands, edited by Eric Waddell, Vijay Naidu, and Epeli Hau'ofa, 2-I6. Suva: University of the South Pacific. Reprinted in The Contemporary Pacific 6:I47-I6I (I994).

Hereniko, Vilsoni

I995 Woven Gods: Female Clowns and Power in Rotuma. Pacific Islands Monograph Series I 2. Honolulu: Center for Pacific Islands Studies and University of Hawai'i Press.

Hereniko, Vilsoni, and Rob Wilson, editors

I999 Inside Out: Literature, Cultural Politics, and Identity in the New Pacific. Lanham, MD: Rowman \& Littlefield Publishers.

Hofstetter, Fred T

I997 Cognitive Versus Behavioral Psychology. Presentation during рвS videoconference entitled, The World Wide Web: Gateway to Effective Learning, I7 April, < http://www.udel.edu/fth/pbs/webmodel.htm >

Howard, Alan

I999 Pacific-Based Virtual Communities: Rotuma on the World Wide Web. The Contemporary Pacific II:I60-I75.

Naidu, Vijay

I998 No Pacific Studies, We're usp. The Journal of Pacific Studies 22:I9I205 .

Ogden, Michael R

I995 Pacific Islands Information Technology and Universal Access: It's Not Just about Wires. Development Bulletin 35:I9-22. Also at <http:// www2.hawaii.edu/ ogden/piir/pacific/NJAW.html>

I999 Islands on the Internet. The Contemporary Pacific I I:45 I-465.

Said, Edward W

I978 Orientalism. New York: Vintage Books.

I99I The Politics of Knowledge. Raritan I I (I): I7-3I.

2000 An Interview From Afar (Middle East). In Remembrance of Pacific Pasts, edited by Robert Borofsky, 443-452. Honolulu: University of Hawai'i Press. 
Schutte, Jerald G

I996 Virtual Teaching in Higher Education: The New Intellectual Superhighway or Just Another Traffic Jam? California State University, Northridge, Department of Sociology webpages:

<http://www.csun.edu/sociology/virexp.htm >

Smith, Linda Tuhiwai

1999 Decolonizing Methodologies: Research and Indigenous Peoples. London: Zed Books.

Teaiwa, Teresia

200I Lo(o)sing the Edge. The Contemporary Pacific I3:343-357.

Thaman, Konai Helu

I993 Culture and the Curriculum. Comparative Education in the South

Pacific 29 (3): 249-260.

UsP, University of the South Pacific

2000 USPNet 2000. <http://www.usp.ac.fj/uspnet/>

Wesley-Smith, Terence

I995 Rethinking Pacific Islands Studies. Pacific Studies I 8 (2): I I 5-I 37.

\section{Abstract}

The paper explores how the Internet can be used to enhance the quality of teaching and learning in Pacific Islands studies. It does so with reference to an experimental web-based interactive module that linked classes at University of Hawai' $i$ and Canterbury University in fall 2000 as part of the Ford-funded project, Moving Cultures: Remaking Asia-Pacific Studies. The paper argues that such interactive pedagogies can be used to redress some of the power imbalances apparent in the field of study and help accelerate an ongoing process of decolonization.

KEYWORDS: cyberspace, decolonization, interactive learning, Pacific Islands studies, pedagogy 